The Journal of Vitaminology 13, 64-69 (1967)

\title{
ON THE EFFECTS OF ZINC AND CADMIUM IONS ON THE NEW FLAVIN PHOSPHATE-PRODUCING ACTIVITY OF RHIZOPUS JAVANICUS
}

\author{
SEI TACHIBANA AND KAGEYASU MIKI ${ }^{2}$ \\ Department of Chemistry, Faculty of Science and Engineering, \\ Ritsumeikan University, Kita-ku, Kyoto \\ (Received September 8, 1966)
}

It has been previously reported (1) that $\mathrm{Zn}^{2+}$ and $\mathrm{Cd}^{2+}$ have remarkably opposite effects on riboflavin cyclic $2^{\prime}, 5^{\prime}$-monophosphate $\left(\mathrm{FMN}^{\prime}\right)$ production by Rhizopus oryzae as well as on its growth and on its acid production. When $\mathrm{Zn}^{2+}$ was added to the culture medium, the $\mathrm{FMN}^{\prime}$-producing activity was depressed, while the growth was accelerated. On the contrary, in the case of $\mathrm{Cd}^{2+}$, the $\mathrm{FMN}^{\prime}$ producing activity was stimulated, while the growth was inhibited.

In this paper, the effects of these ions on $R h$. javanicus are reported.

\section{EXPERIMENTAL}

\section{Dry Mycelium}

$R h$. javanicus was cultured stationaly in the basal medium of Fernbach consisting of $3 \mathrm{~g}$ glucose, $0.1 \mathrm{~g} \mathrm{NH} \mathrm{NH}_{3}, 0.1 \mathrm{~g} \mathrm{NaNO}, 0.1 \mathrm{~g} \mathrm{KH}_{2} \mathrm{PO}_{4}, 0.05 \mathrm{~g} \mathrm{MgSO}_{4}$, $0.05 \mathrm{~g} \mathrm{KCl}, 1 \mathrm{~g} \mathrm{CaCO}_{3}$ in $100 \mathrm{ml}$ deionized water for $7-9$ days at $30^{\circ}$. After harvest, the mycelia were washed and dried in $\mathrm{CaCl}_{2}$-desiccator for 6 days, and they were used for the test of the effect of ions.

\section{Reaction Mixture and Condition}

The composition of the reaction mixture is as follows: $50 \mathrm{mg}$ dry mycelia, $2.5 \mathrm{ml} 0.02 \%$ riboflavin solution, $1 \mathrm{ml} 0.2 \mathrm{M}$ phosphate buffer $(\mathrm{pH} 6.2), 10^{-4}, 10^{-3}$ or $5 \times 10^{-3} \mathrm{M} \mathrm{Zn}^{2+}$ or $10^{-6}, 10^{-5}$ or $5 \times 10^{-5} \mathrm{M} \mathrm{Cd}^{2+}$ and water in a volume of $5 \mathrm{ml}$. After addition of $0.2 \mathrm{ml}$ toluene, the mixture was incubated for $24-96$ hours at $37^{\circ}$.

\section{Assay of the Reaction Product}

One $\mathrm{ml}$ aliquot of the reaction mixture was subjected to paper chromatography after 24, 48 and 96 hour incubation. Solvent system of $n$-butanol-80\% formic acid-water $(4: 1: 1)$ was used. It cannot separate $\mathrm{FMN}$ from $\mathrm{FMN}^{\prime}$, but no detectable formation of FMN took place under the condition.

4. Culture Test

$R h$. javanicus was cultured stationarily for 7 days at $30^{\circ}$ on $20 \mathrm{ml}$ of the basal medium to which the two ions of the concentrations mentioned above, or

\footnotetext{
1 This paper was read at the Annual Meeting of the Soc. of Fermentation Tech. Jap. (November, 1965, Osaka).

2 立花 精, 三木影靖.
} 
$10 \mathrm{mg}$ riboflavin had been co-added. After filtration, the mycelia harvested were washed, dried in a $\mathrm{CaCl}_{2}$-desiccator, weighed and used for enzymatic reaction. FMN' in the reaction mixture was determined by the procedure mentioned above. $\mathrm{Ca}$ of the calcium salt of the organic acid produced and the residual sugar were analysed by the method of EDTA and of Bertrand, respectively.

5. Test of the Enzymatic Activity of the Ion-Grown Mycelia

The reaction mixture mentioned above from which $\mathrm{Zn}^{2+}$ and $\mathrm{Cd}^{2+}$ had been omitted was used for the enzyme activity test of the ion-grown mycelia.

\section{RESULTS}

\section{Effect of Zinc Ions}

Fig. 1 shows the effect of $\mathrm{Zn}^{2+}$ on $\mathrm{FMN}^{\prime}$-forming activity of the two mycelia harvested after 7 and 9 day-incubation when it was added to the reaction mixture.

$\mathrm{Zn}^{2+}$ in the range of $10^{-4}, 10^{-3}$ and $5 \times 10^{-3} \mathrm{M}$ exhibited inhibitory effect which continued 96 hours in each case.

Fig. 2 shows the effect of $\mathrm{Zn}^{2+}$ added to the culture medium. As shown in A, the activity of zinc-grown mycelia was depressed inversely to the increase of the amount of zinc added. As shown in B, the mycelial weight was much increased corresponding to the increase of zinc. Moreover, the yield of fumaric acid markedly decreased by the addition of $\mathrm{Zn}^{2+}$.

When riboflavin was co-added with $\mathrm{Zn}^{2+}$, as shown in Fig. 3, the effect of $\mathrm{Zn}^{2+}$ on the FMN'-producing activity was not so significant as by its sole addition. Such influence of riboflavin was also observed on the details of mycelial weight or acid production.- Therefore, riboflavin added to the culture medium seems to have reduced the effect of zinc.

\section{Effect of Cadmium Ions}

Fig. 4 shows the effect of $\mathrm{Cd}^{2+}$ added to the reaction mixture with dry mycelia. The concentration was $10^{-6}, 10^{-5}$ or $5 \times 10^{-5} \mathrm{M}$. It was lower than that of $\mathrm{Zn}^{2+}$, because so vigorous effect as in $R h$. oryzae was expected.

After 24 hour-incubation, $\mathrm{Cd}^{2+}$ exhibited an inhibitory effect to $\mathrm{FMN}^{\prime}$ formation of dry mycelia of 7 and 8 day-culture. It was apparently reduced after 96 hours. These findings were entirely resembled to the effect of $\mathrm{Cd}^{2+}$ on $R h$. oryzae.

Subsequently, the effect of $\mathrm{Cd}^{2+}$ added to the culture medium was investigated. As shown in Fig. 5, it was revealed that the activity of cadmium-grown mycelia was, on the contrary, much higher than the control mycelia. As shown in B, by the addition of $\mathrm{Cd}^{2+}$ the growth was markedly inhibited, though no inhibitory effect was observed on the sugar consumption. It was of interest that the more $\mathrm{Cd}^{2+}$ was added, the more the ratio of the acid produced to the mycelia synthesized was increased. In the case of $\mathrm{Zn}^{2+}$, the ratio was significantly decreased with the increased amount of $\mathrm{Zn}^{2+}$

As shown in Fig. 6, even when riboflavin was co-added to the culture medium, the stimulative effect of $\mathrm{Cd}^{2+}$ was so significant that the $\mathrm{FMN}^{\prime}$-forming activity of the mycelia harvested from the $5 \times 10^{-5} \mathrm{M} \mathrm{Cd}^{2+}$-containing medium was $50-95 \%$ higher than the control after 24-96 hour incubation. In this case, the growth inhibition by $\mathrm{Cd}^{2+}$ was also so significant. 


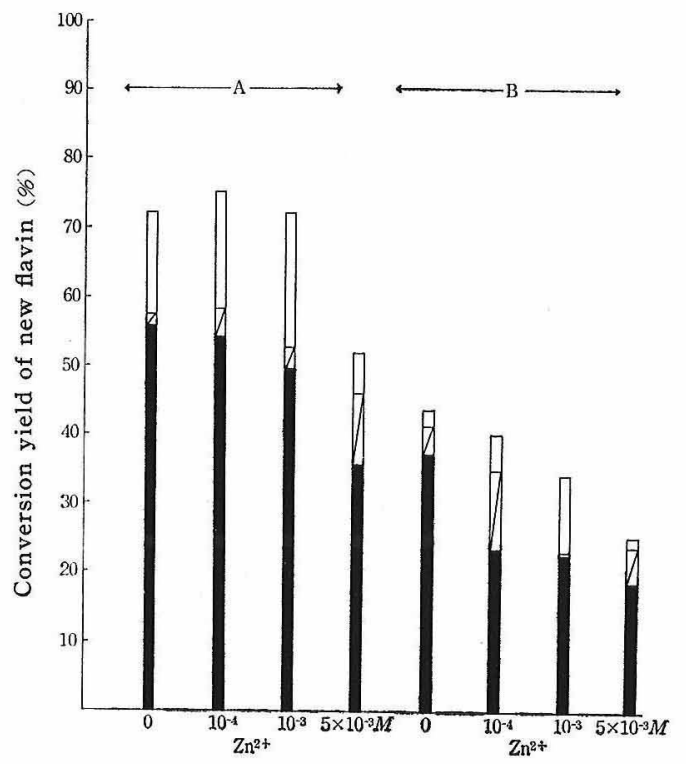

FIG. 1 Effect of $\mathrm{Zn}^{2+}$ Added to the Reaction Mixture $\square, 96-\mathrm{hr}$ incubation; $\square, 48-\mathrm{hr}$ incubation; $\mathbf{n}, 24 \mathrm{-hr}$ incubation. A, mycelia of 7-day culture; B, mycelia of 9-day culture.

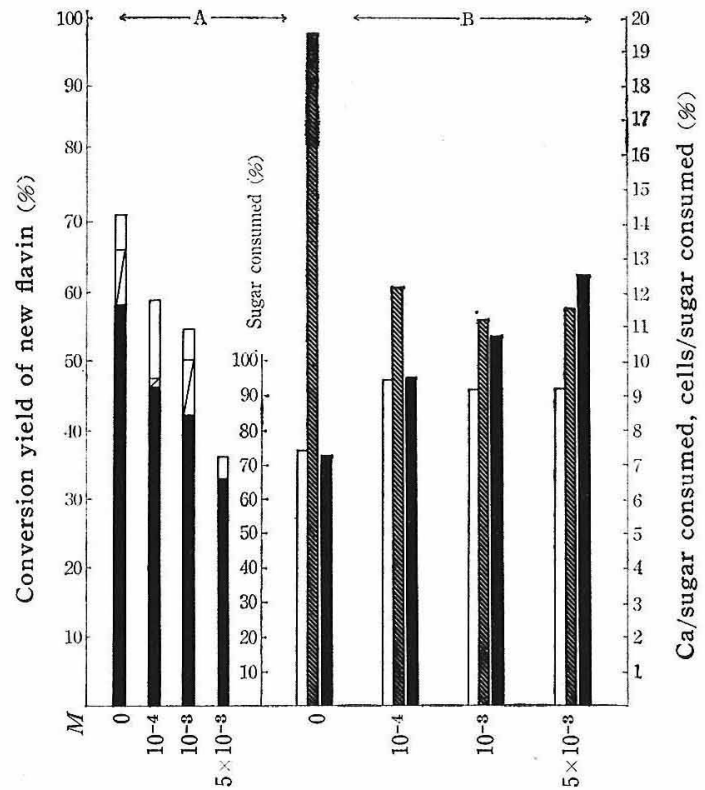

FIG. 2 Effect of $\mathrm{Zn}^{2+}$ Added to the Culture Medium

A. Activity of mycelium.

$\square, 96-\mathrm{hr}$ incubation; $\square, 48 \mathrm{hr}$ incubation; $\square, 24 \mathrm{hr}$ incubation.

B. Effects on sugar consumption, acid production and mycelial weight. $\square$, sugar consumed $(\%)$; 嬨, Ca/sugar consumed $(\%) ;$ consumed $(\%)$. 


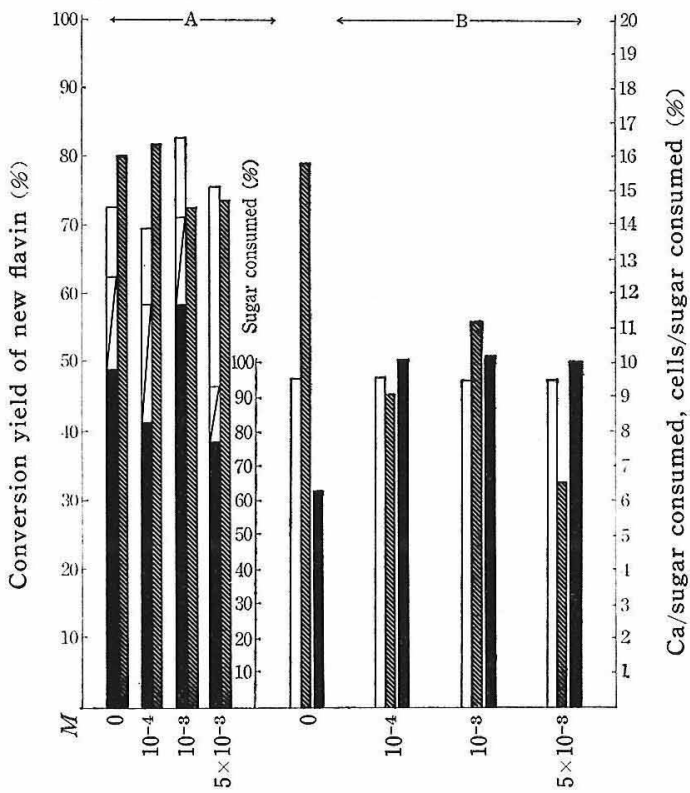

FIG. 3 Effect of $\mathrm{Zn}^{2+}$ Co-added with Riboflavin in Culture Medium A. Activity of mycelia.

$\square, 96-\mathrm{hr}$ incubation; $\square, 48 \mathrm{hr}$ incubation a, 24-hr incubation; 耀, culture medium.

B. Effects on sugar consumption, acid production and mycelial weight. $\square$, sugar consumed $(\%)$; sugar consumed $(\%)$.

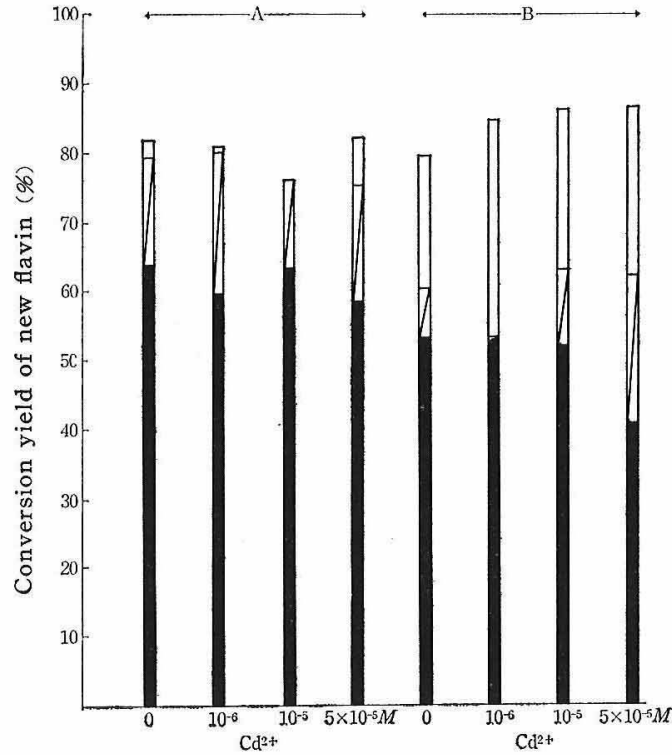

FIG. 4 Effect of $\mathrm{Cd}^{2+}$ Added in the Reaction Mixture $\square, 96-\mathrm{hr}$ incubation; $\nearrow, 48-\mathrm{hr}$ incubation;, $24-\mathrm{hr}$ incubation. A, mycelia of 7-day culture; B, mycelia of 8-day culture. 


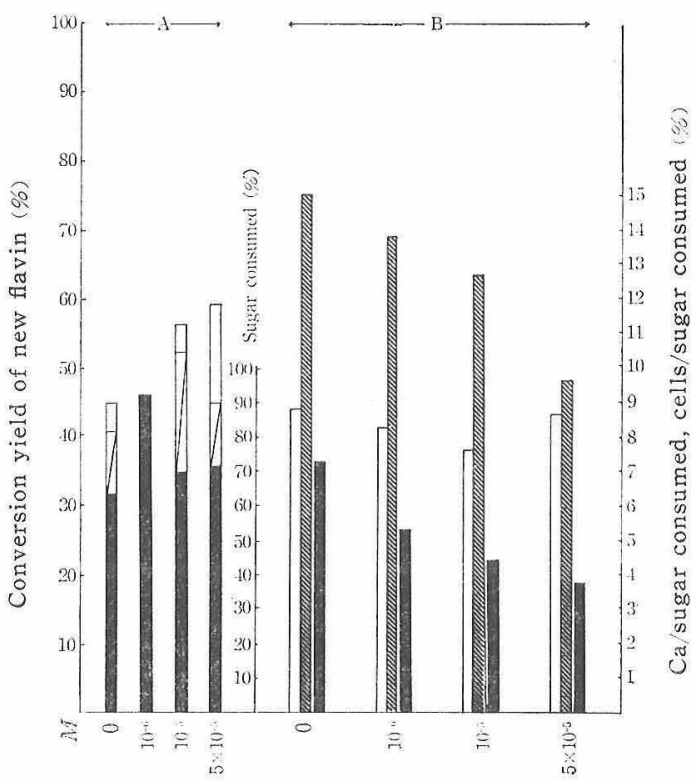

Fig. 5 Effect of $\mathrm{Cd}^{2+}$ Added in Culture Medium

A. Activity of mycelia.

प, 96-hr incubation; Д, 48-hr incubation; ㅁ, 24-hr incubation.

B. Effects on sugar consumption, acid production and mycelial weight. $\square$, sugar consumed $(\%)$;, $\mathrm{Ca} /$ sugar consumed $(\%)$; 圆, cells/sugar consumed (O)

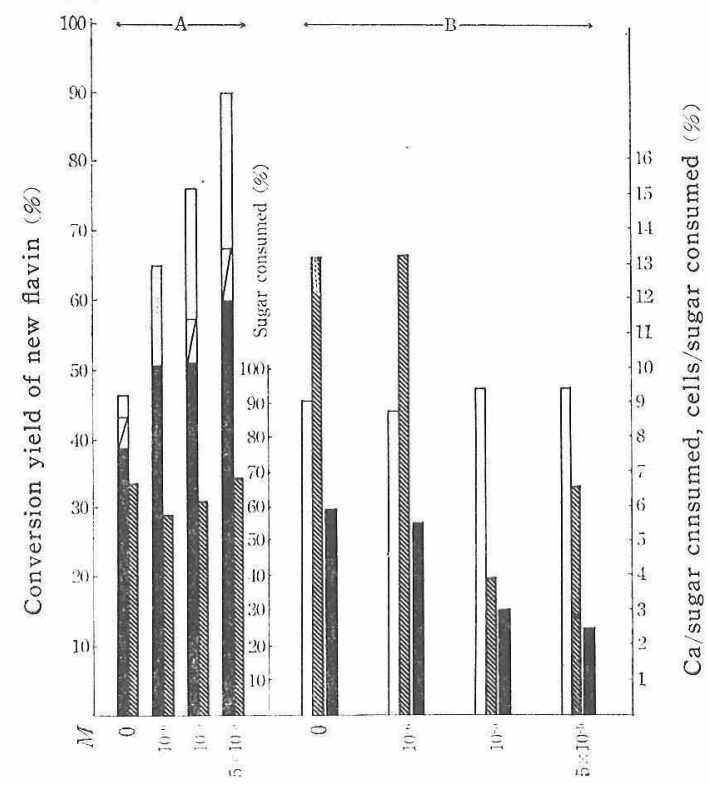

Fig. 6 Effect of $\mathrm{Cd}^{2+}$ Co-added with Riboflavin in Culure Medium

A. Activity of mycelia.

$\square$, 96-hr incubation; $\Pi$, 48-hr incubation ;

回, 24-hr incubation: , culture medium.

B. Effects on sugar consumption, acid production and mycelial weight. $\square$, sugar consumed ( $\left.\sigma^{\prime}\right)$; , Ca/sugar consumed $(\%)$; 圆, cells/ sugar consumed $(0,0)$. 


\section{DISCUSSION}

By the experiment with $R h$. oryzae, as previously reported (2), it was revealed that $\mathrm{Fe}^{3+}$, which was found more effective than $\mathrm{Zn}^{2+}$ in respect to growth promotion and $\mathrm{FMN}^{\prime}$-synthesis depression, caused more remarkable contrast of the two respects than $\mathrm{Zn}^{2+}$.

Effects of $\mathrm{Cd}^{2+}$ shown in this report coincided with those of the previous report using $R$ h. oryzae in respect to growth inhibition and $\mathrm{FMN}^{\prime}$-synthesis promotion.

The effect of $\mathrm{Cd}^{2+}$ seems to be stimulative on the synthesis of $\mathrm{FMN}^{\prime}$-forming enzyme, because $\mathrm{Cd}^{2+}$-grown mycelia exhibited higher activity despite of its inhibitory effect on $\mathrm{FMN}^{\prime}$-producing activity of dry mycelia when added to the reaction mixture.

These evidences suggest that $F N^{\prime}$ or $F M N^{\prime}$-forming enzyme may play a role of regulatory effector between growth and acid production of Rhizopus, depressing the former and accelerating the latter.

\section{SUMMARY}

1. By addition of $10^{-4}$ to $5 \times 10^{-3} M \mathrm{Zn}^{2+}$ in the reaction mixture, FMN'-producing activity of the dry mycelia of $R h$. javanicus was inhibited.

2. Addition of $10^{-4}$ to $5 \times 10^{-3} \mathrm{M} \mathrm{Zn}^{2+}$ to the culture medium stimulated the growth and depressed the acid production.

3. The zinc-grown mycelia exhibited lower FMN'-forming activity.

4. Co-addition of riboflavin to $\mathrm{Zn}^{2+}$ reduced the effects caused by the sole addition of $\mathrm{Zn}^{2+}$.

5. By addition of $10^{-6}$ to $5 \times 10^{-5} \mathrm{M} \mathrm{Cd}^{2+}$ in the reaction mixture, $\mathrm{FMN}^{\prime}$-producing activity of the dry mycelia of the mold was inhibited, but the inhibition was reduced when incubation was prolonged.

6. Addition of $10^{-6}$ to $5 \times 10^{-5} \mathrm{M} \mathrm{Cd}^{2+}$ to the culture medium markedly inhibited the growth, without marked inhibition of acid production.

7. The cadmium-grown mycelia exhibited higher FMN'-producing activity than the control.

8. Co-addition of riboflavin with $\mathrm{Cd}^{2+}$ failed to reduce the effects caused by the sole addition of $\mathrm{Cd}^{2+}$.

9. From these evidences, it was assumed that $\mathrm{FMN}^{\prime}$ or $\mathrm{FMN}^{\prime}$-forming enzyme might play a role of regulator between growth and acid production.

\section{REFERENCES}

1. Tachibana, S., Siode, J., and Takenaka, H., Vitamins 30, 247 (1964).

2. Tachibana, S., Takenaka, H., and Shiode, J., Vitamins 30, 251 (1964). 